\title{
Analysis of Malondialdehyde, Chlorophyll Proline, Soluble Sugar, and Glutathione Content in Arabidopsis seedling
}

Zhijin Zhang, Rongfeng Huang*

Cold and Arid Regions Environmental and Engineering Research Institute, Chinese Academy of Sciences, Lanzhou, China

*For correspondence: rfhuang@caas.cn

[Abstract] The protocol has four sub-protocols, which are about the measurement of malondialdehyde, chlorophyll proline, soluble sugar, and glutathione content, respectively, in Arabidopsis seedlings by using spectrophotometer. These methods are simple, effective and reproducible, which will help the researchers who are not familiar with these approaches, quickly get reliable results.

\section{A. Measurement of Malondialdehyde}

\section{Materials and Reagents}

1. Thiobarbituric acid (TBA) (Sigma-Aldrich, catalog number: T5500)

2. Trichloroacetic acid (TCA) (Sigma-Aldrich, catalog number: T9159)

3. Malondialdehyde (MDA) (BOC Sciences, catalog number: 542-78-9)

\section{Equipment}

1. Centrifuge

2. Spectrophotometer

\section{Procedure}

Note: The experiment is done at room temperature (RT) except of specific indication.

1. $0.1 \mathrm{~g}$ leaf tissue (with similar age, and young expanded leaf may be better) is ground into powder with liquid nitrogen, and then put the powder into a tube containing $1 \mathrm{ml} 0.1 \%$ $(w / v)$ TCA and mix by inverting the tube to homogenize the leaf tissue.

2. Centrifuge homogenized samples at $10,000 \times \mathrm{g}$ for $10 \mathrm{~min}$, and then transfer supernatant to a new tube.

3. $4 \mathrm{ml}$ of $20 \%$ TCA containing $0.5 \%$ TBA was added to the supernatant and mixed well. 
4. The mixture is boiled at $95^{\circ} \mathrm{C}$ for $15 \mathrm{~min}$ and quickly cooled on ice (TBA can interact with MDA and results into red compound in acidic buffer, so the content of MDA can be calculated by measuring the density of the resulting red compound with spectrophotometer at $532 \mathrm{~nm}$. The high temperature can accelerate the reaction and low temperature can inhibit it).

5. Centrifuge the mixture at $10,000 \times g$ for $5 \mathrm{~min}$, and then transfer supernatant to a new tube.

6. To generate a standard curve, a serial concentration of MDA is made: $1 \mu \mathrm{M}, 2 \mu \mathrm{M}, 5 \mu \mathrm{M}$, $10 \mu \mathrm{M}, 20 \mu \mathrm{M}$ and $50 \mu \mathrm{M}$ (the volume of each dilution depends on the size of the cuvette of spectrophotometer).

7. Measure the optical density of standard samples from step 6 at $532 \mathrm{~nm}$ by spectrophotometer and make the standard curve to get the extinction coefficient (Figure 1).

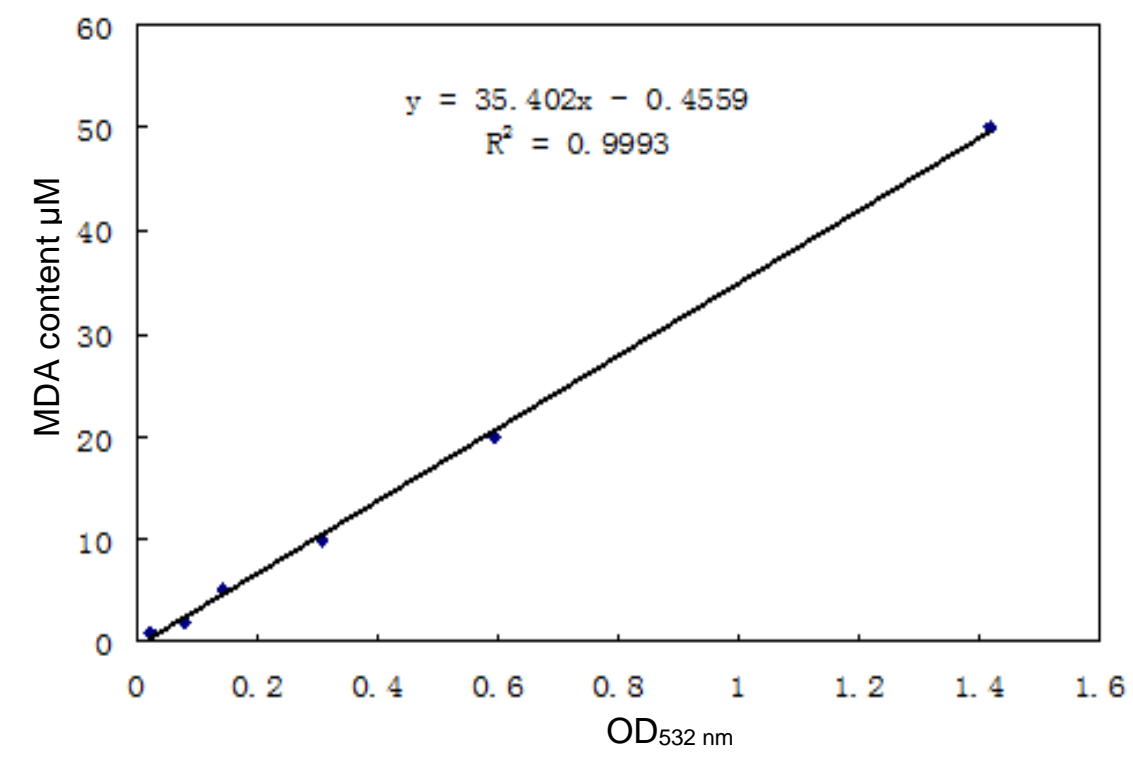

Figure 1. The standard curve of MDA

8. Measure the optical density of plant samples from step 5 at $532 \mathrm{~nm}$ and calculate the content of MDA according to the standard curve (Madhava Rao and Sresty, 2000; Baryla et al., 2000) 


\section{B. Measurement of chlorophyll}

\section{Materials and Reagents}

1. Dimethyl formamide (DMF) (Sigma-Aldrich, catalog number: D4551)

\section{Equipment}

1. Centrifuges

2. Spectrophotometer

\section{Procedure}

Note: The experiment is done at room temperature.

1. $0.1 \mathrm{~g}$ leaf tissue is ground into powder with liquid nitrogen, and then homogenized with 1 $\mathrm{ml}$ 100\% DMF.

2. Centrifuge homogenized samples at $10,000 \times \mathrm{g}$ for $10 \mathrm{~min}$, and then gather the supernatant.

3. Measure the optical density of the supernatant at $664 \mathrm{~nm}$ and $647 \mathrm{~nm}$, respectively.

4. Calculate the content of chlorophyll a and chlorophyll $b$ by the following formulas (Sibley et al.,1996; Inskeep and Bloom, 1985; Aono et al., 1993):
a. $\quad$ chlorophyll a] $=12.7 \times A_{664}-2.79 \times A_{647}$
b. $\quad$ chlorophyll b] $=20.7 \times A_{647}-4.62 \times A_{664}$
c. $\left[\right.$ chlorophyll a + chlorophyll b] $=17.90 \times A_{647}+8.08 \times A_{664}$

\section{Measurement of Proline}

\section{Materials and Reagents}

1. Sulphosalicylic acid (DingGuo, catalog number: DS094)

2. Proline (Sigma-Aldrich, catalog number: 858919)

3. Ninhydrin (Sigma-Aldrich, catalog number: 151173)

4. Acetic acid (DingGuo, catalog number: DS002)

5. Orthophosphate (Sigma-Aldrich, catalog number: P2023)

6. Toluene (Sigma-Aldrich, catalog number: 650579)

7. Ninhydrin reagent (see Recipes) 


\section{Equipment}

1. Centrifuges

2. Spectrophotometer

\section{Procedure}

Note: The experiment is done at room temperature (RT) except of specific indication.

1. To generate a standard curve, a serial concentration of Proline is made in $3 \%$ sulphosalicylic acid: $1 \mu \mathrm{M}, 10 \mu \mathrm{M}, 50 \mu \mathrm{M}, 100 \mu \mathrm{M}, 150 \mu \mathrm{M}, 200 \mu \mathrm{M}, 300 \mu \mathrm{M}, 1 \mathrm{ml}$ for each dilution.

2. Each $500 \mu \mathrm{l}$ standard solution is added with $500 \mu \mathrm{l}$ acetic acid and $500 \mu \mathrm{l}$ ninhydrin reagent in $5 \mathrm{ml}$ tube and boil for $45 \mathrm{~min}$, and then cooled in ice for $30 \mathrm{~min}$.

3. Add equal volume toluene to each sample and vibrate for $1 \mathrm{~min}$, and then centrifuge at $1,000 \times g$ for 5 min.

4. Measure the optical density of toluene solution at $520 \mathrm{~nm}$ by spectrophotometer and make the standard curve (Figure 2).

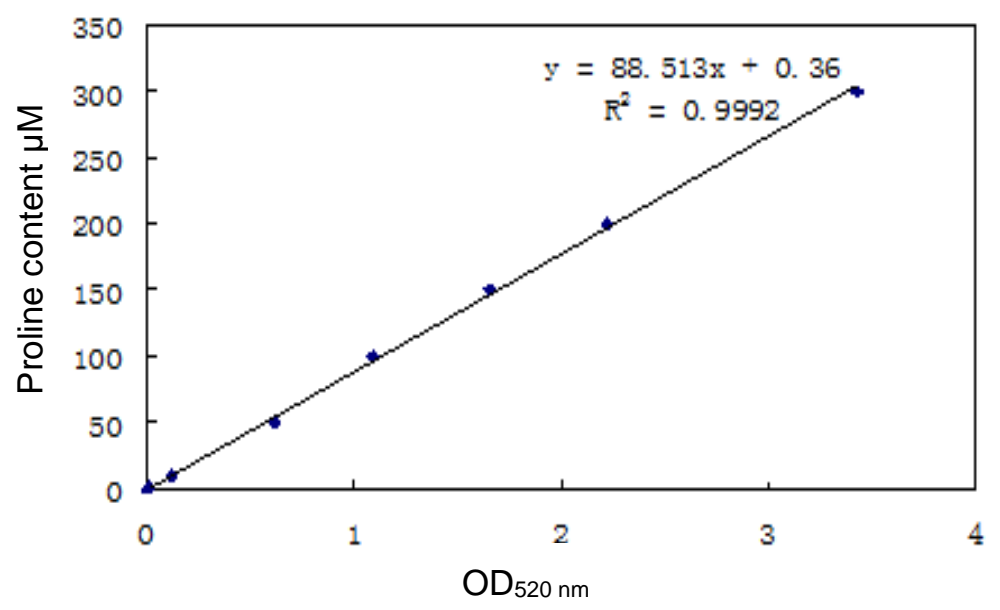

\section{Figure 2. The standard curve of proline}

5. $\quad 0.5 \mathrm{~g}$ plant sample is ground into powder with liquid nitrogen, and then homogenized with $2 \mathrm{ml}$ of $3 \%$ sulphosalicylic acid in tube.

6. Centrifuge homogenized samples at 5,000 $\times \mathrm{g}$ for $5 \mathrm{~min}$, and then collect the supernatant

7. The supernatant is treated as steps 2 and 3 , and measure the optical density of samples as step 4, and then calculate the content of praline using the standard curve from step 3 (Bates et al., 1973; Lattanzioa et al., 2009). 


\section{$\underline{\text { Recipes }}$}

1. Ninhydrin reagent

$2.5 \mathrm{~g}$ ninhydrin is successively added to $60 \mathrm{ml}$ Glacial Acetic acid and $40 \mathrm{ml} 6 \mathrm{M}$ orthophosphate, and then dissolved at $70{ }^{\circ} \mathrm{C}$. After cool down, the reagent can be stored in brown bottle at $4{ }^{\circ} \mathrm{C}$ for less than $24 \mathrm{~h}$.

\section{Measurement of soluble sugar}

\section{Materials and Reagents}

1. Ethanol (DingGuo, catalog number: DS023)

2. Glucose (DingGuo, catalog number: DS063)

3. Anthrone (SCRC, catalog number: 30015014)

4. $\mathrm{H}_{2} \mathrm{SO}_{4}$ (Sigma-Aldrich, catalog number: 339741 )

5. Thiourea (Amresco, catalog number: M222)

6. Chloroform (Sigma-Aldrich, catalog number: C2432)

7. Anthrone reagent (see Recipes)

\section{Equipment}

1. Centrifuges

2. Spectrophotometer

3. Shaker

\section{Procedure}

Note: The experiment is done at room temperature (RT) except of specific indication.

1. To generate a standard curve, a serial concentration of glucose is made: $1 \mu \mathrm{M}, 10 \mu \mathrm{M}, 50$ $\mu \mathrm{M}, 100 \mu \mathrm{M}, 150 \mu \mathrm{M}, 200 \mu \mathrm{M}, 300 \mu \mathrm{M}, 5 \mathrm{ml}$ for each concentration of glucose solution.

2. $50 \mu \mathrm{l}$ of each diluted glucose solution is mixed with $4.95 \mathrm{ml}$ anthrone reagent and then boiled for $15 \mathrm{~min}$.

3. Measure the optical density of glucose standards at $620 \mathrm{~nm}$ by spectrophotometer to generate a standard curve.

4. $0.1 \mathrm{~g}$ dried sample is ground into powder with liquid nitrogen, and then homogenized with $2 \mathrm{ml} 80 \%$ ethanol in shaker at $200 \mathrm{rpm}$ in $50 \mathrm{ml}$ tube for $1 \mathrm{~h}$. 
5. Centrifuge at $6,000 \times g$ for $10 \mathrm{~min}$, and then transfer as much supernatant as possible into a new $5 \mathrm{ml}$ tube.

6. Add equal volume of chloroform, completely mix, and then centrifuge at $12,000 \times g$ for 10 $\min$.

7. The aqueous part is transferred to a new tube and repeat steps 2 and 3 to measure the optical density of the sample. The content of soluble sugar is calculated according the standard curve made at step 3 (Mandre et al., 2002; Jin et al., 2007).

\section{$\underline{\text { Recipes }}$}

1. Anthrone reagent

$72 \% \mathrm{H}_{2} \mathrm{SO}_{4}$

$500 \mathrm{mg} / \mathrm{L}$ anthrone

$10 \mathrm{~g} / \mathrm{L}$ thiourea

\section{E. Measurement of Glutathione}

\section{Materials and Reagents}

1. Trichloroacetic acid (TCA) (Sigma-Aldrich, catalog number: T9159)

2. Polyvinylpolypyrrolidone (PVPP) (Sigma-Aldrich, catalog number: P6755)

3. 2-amino-2-(hydroxymethyl)-1,3-propanediol (TRIS) (DingGuo, catalog number: DH350)

4. 5,50-dithio-bis (2-nitrobenzoic acid) (DTNB) (DingGuo, catalog number: $\mathrm{DH} 499$ )

5. Glutathione reductase (GR) (Merck KGaA, catalog number: 359960)

6. Glutathiol (GSSG) (Solarbio, catalog number: G8690)

7. Reaction solution (see Recipes)

\section{Equipment}

1. Centrifuges

2. Spectrophotometer

\section{Procedure}

Note: The experiment is done at room temperature (RT) except of specific indication.

1. To generate a standard curve, a serial concentration of GSSG is made: $0.5,1,2,5,10,20$ $\mu \mathrm{M}, 2 \mathrm{ml}$ for each dilution of GSSG. 
2. $100 \mu \mathrm{l}$ of each GSSG standard made at step 1 is added to $3 \mathrm{ml}$ of Reaction solution and incubated for $15 \mathrm{~min}$. Then add $100 \mathrm{mM}$ DTNB to a final concentration of $10 \mathrm{mM}$ and incubate at $25^{\circ} \mathrm{C}$ for $15 \mathrm{~min}$.

3. Measure the optical density of each sample at $412 \mathrm{~nm}$ by spectrophotometer, and make standard curve with a function of the concentration of GSSG standard and the optical density of each GSSG standard.

4. $0.5 \mathrm{~g}$ of Arabidopsis leaves is ground in liquid nitrogen.

5. The samples are homogenized with $1 \mathrm{ml}$ extract solution and mixed completely by inverting the tube.

6. The mixture is centrifuged at $10,000 \times \mathrm{g}$ at $4{ }^{\circ} \mathrm{C}$ for $10 \mathrm{~min}$, and then the supernatant is transferred to a new tube.

7. $100 \mu \mathrm{l}$ supernatant is treated as described at step 2, and the optical density of the supernatant is measured at $412 \mathrm{~nm}$ as described at step 3, and calculate the GSSG content of the sample according the standard curve.

8. $100 \mu \mathrm{l}$ supernatant is mixed with $3 \mathrm{ml} 500 \mathrm{mM}$ Tris- $\mathrm{HCl}(\mathrm{pH} 8.0)$ buffer containing $10 \mathrm{mM}$ DTNB and incubated at $25^{\circ} \mathrm{C}$ for $15 \mathrm{~min}$. The optical density is then measured at $412 \mathrm{~nm}$. The Glutathione (GSH) content is determined by the same standard curve as described at step 3 with the following formula: [GSH] $=2 \times$ [standard curve].

9. The total glutathione content $=[$ GSH] + [GSSG] (Huang et al., 2005; Chen et al., 2011)

\section{$\underline{\text { Recipes }}$}

1. Reaction solution

$500 \mathrm{mM}$ Tris- $\mathrm{HCl}(\mathrm{pH} 8.0)$ buffer

$\mathrm{GR}(1 \mathrm{U}$ for each $3 \mathrm{ml}$ reaction solution)

1 mM EDTA

$3 \mathrm{mM} \mathrm{MgCl}_{2}$

$150 \mu \mathrm{M}$ NADPH

2. Extract solution

$0.1 \%$ TCA (pH 2.8)

1 mM EDTA

$1 \%(w / v)$ PVPP

\section{Acknowledgments}

This protocol is adapted from Huang et al. (2005) as well as other works mentioned in the reference list. 


\section{References}

1. Aono, M., Kubo, A., Saji, H., Tanaka, K. and Kondo, N. (1993). Enhanced tolerance to photooxidative stress of transgenic Nicotiana tabacum with high chloroplastic glutathione reductase activity. Plant Cell Physiol 34(1): 129-135.

2. Baryla, A., Laborde, C., Montillet, J. L., Triantaphylides, C. and Chagvardieff, P. (2000). Evaluation of lipid peroxidation as a toxicity bioassay for plants exposed to copper. Environ Pollut 109(1): 131-135.

3. Bates, L., Waldren, R. and Teare, I. (1973). Rapid determination of free proline for water-stress studies. Plant Soil 39(1): 205-207.

4. Chen, L., Han, Y., Jiang, H., Korpelainen, H. and Li, C. (2011). Nitrogen nutrient status induces sexual differences in responses to cadmium in Populus yunnanensis. $\mathrm{J}$ Exp Bot 62(14): 5037-5050.

5. Huang, C., He, W., Guo, J., Chang, X., Su, P. and Zhang, L. (2005). Increased sensitivity to salt stress in an ascorbate-deficient Arabidopsis mutant. J Exp Bot 56(422): 3041-3049.

6. Inskeep, W. P. and Bloom, P. R. (1985). Extinction coefficients of chlorophyll a and B in n,n-dimethylformamide and 80\% acetone. Plant Physiol 77(2): 483-485.

7. Jin, Z. M., Wang, C. H., Liu, Z. P. and Gong, W. J. (2007). Physiological and ecological characters studies on Aloe vera under soil salinity and seawater irrigation. Process Biochem 42(4): 710-714.

8. Lattanzio, V., Cardinali, A., Ruta, C., Fortunato, I. M., Lattanzio, V. M., Linsalata, V. and Cicco, N. (2009). Relationship of secondary metabolism to growth in oregano (Origanum vulgare L.) shoot cultures under nutritional stress. Environ Exp Bot 65(1): 54-62.

9. Madhava Rao, K. V. and Sresty, T. V. (2000). Antioxidative parameters in the seedlings of pigeonpea (Cajanus cajan (L.) Millspaugh) in response to $\mathrm{Zn}$ and Ni stresses. Plant Sci 157(1): 113-128.

10. Mandre, M., Tullus, H. and Kloseiko, J. (2002). Partitioning of carbohydrates and biomass of needles in Scots pine canopy. Z Naturforsch C 57(3-4): 296-302.

11. Sibley, J. L., Eakes, D. J., Gilliam, C. H., Keever, G. J., Dozier, W. A. and Himelrick, D.G. (1996). Foliar SPAD-502 meter values, nitrogen levels, and extractable chlorophyll for red maple selections. Hort Sci 31(3): 468-470. 